\title{
Role of Plasma Vasopressin in Impaired Water Excretion of Glucocorticoid Deficiency
}

\author{
John Boykin, ANTOINe DeTorrente, AbBy Erickson, Gary Robertson, and \\ ROBERT W. SCHRIER, University of Colorado Medical Center, Denver, Colorado \\ 80262 and Indiana University School of Medicine, Indianapolis, Indiana 46202
}

A B S T R A C T In the present study, the effect of selective glucocorticoid deficiency on renal water excretion was investigated in conscious, trained, adrenalectomized dogs. The animals were studied before and after a water load while on replacement therapy of desoxycorticosterone acetate, $5 \mathrm{mg} /$ day, and dexamethasone, $0.8 \mathrm{mg} /$ day (group I), and while off dexamethasone for 5-9 days (group II). Before the water load the weight, inulin space, cardiac output, blood pressure, glomerular filtration rate, renal blood flow, plasma osmolality, and plasma antidiuretic hormone measured by radioimmunoassay were similar in both groups I and II. However, after a $40 \mathrm{ml} / \mathrm{kg}$ water load a marked impairment in renal water excretion in the glucocorticoid deficient dogs became apparent. Maximal free water clearance was $-0.046 \pm 0.16$ vs. $6.51 \pm 0.72 \mathrm{ml} / \mathrm{min}(P<0.001)$ and minimal urinary osmolality was $425 \pm 56$ vs. $82 \pm 3.5 \mathrm{mosmol} / \mathrm{kg} \mathrm{H}_{2} \mathrm{O}$ $(P<0.001)$ in group II as compared to group I. Plasma antidiuretic hormone was maximally suppressed during the water load in group I to $0.34 \pm 0.08 \mathrm{pg} / \mathrm{ml}$ but remained elevated at $9.18 \pm 1.79 \mathrm{pg} / \mathrm{ml}(P<0.005)$ in group II. This nonsuppressibility of plasma antidiuretic hormone during water loading in group II was associated with a significant tachycardia of $145 \pm 6$ vs. $87 \pm 6$ beats/min $(P<0.001)$ in group $I$ and a significantly lower stroke volume of $27 \pm 0 \mathrm{vs.} 59 \pm 0.5 \mathrm{ml} / \mathrm{beat}$ $(P<0.001)$. In conclusion, our results implicate a persistent secretion of antidiuretic hormone as an important factor in the impaired water excretion of glucocorticoid deficiency. A deleterious effect of glucocorticoid deficiency on cardiac function was observed and this hemodynamic alteration could be involved in initiating a nonosmolar, baroreceptormediated release of vasopressin.

\section{INTRODUCTION}

In both man and experimental animals adrenal insufficiency has been associated with an impaired abil-

Received for publication 1 April 1977 and in revised form 17 April 1978. ity to achieve maximal urinary dilution (1-15). The mechanism involved in this impairment of water excretion has been debated for many years and currently two main explanations are offered. One explanation is that water impermeability of the distal nephron is incomplete in the absence of glucocorticoid hormones even though antidiuretic hormone, arginine vasopressin (AVP), is suppressed maximally $(8,16){ }^{1}$

In contrast, other authors have suggested that with glucocorticoid deficiency, AVP is not suppressed maximally during water loading and thus accounts for the impaired urinary dilution $(10,15)$. There is some evidence for both of these theories, because either suppressed $(8,16)$ or elevated $(9,17)$ plasma levels of AVP have been reported during adrenal insufficiency with bioassay techniques.

Another matter of debate is the relative roles of mineralocorticoid and glucocorticoid deficiency. In previous studies from our laboratory mineralocorticoid replacement alone was demonstrated to correct totally the impaired water excretion in conscious adrenalectomized dogs. The duration of withdrawal of glucocorticoid hormone replacement from these animals, however, ranged from 50 to $100 \mathrm{~h}$ (18).

The purpose of the present study was to further examine the mechanisms whereby prolonged glucocorticoid deficiency (5-9 days) in the absence of mineralocorticoid deficiency impairs renal water excretion in trained conscious adrenalectomized dogs. Our results demonstrate that during glucocorticoid deficiency water loaded animals do not suppress plasma AVP as measured by radioimmunoassay. A nonosmolar stimulus initiated by impaired cardiac function may be responsible for the persistence of high

\footnotetext{
${ }^{1}$ Abbreviations used in this paper: AVP, arginine vasopressin; $\mathrm{CH}_{2} \mathrm{O}$, free water clearance; Cosm, osmolar clearance; CPAH, clearance of PAH; DEX, dexamethasone; DOCA, desoxycorticosterone acetate; GFR, glomerular filtration rate; PAH, $p$-amino-hippurate; Posm, plasma osmolality; Uosm, urinary osmolality.
} 
plasma levels of AVP in the glucocorticoid-deficient animal.

\section{METHODS}

18 studies were performed on six trained conscious dogs that weighed 18.2 to $26.8 \mathrm{~kg}$. At least 4 wk before study, each animal underwent bilateral adrenalectomy via a midline incision under pentobarbital sodium anesthesia. 2 days before surgery and daily thereafter until study the dogs were maintained on $0.8 \mathrm{mg}$ dexamethasone (DEX), and $5 \mathrm{mg}$ desoxycorticosterone acetate (DOCA) intramuscularly. Each dog also had one carotid artery exteriorized in a skin tunnel to allow easy vascular access. Completeness of adrenalectomy was assessed by the measurement of plasma cortisol levels after 4 consecutive days of $10 \mathrm{U}$ of adrenocorticotropin hormone intramuscularly. Throughout the entire study the dogs were fed a normal laboratory diet and were allowed to drink tap water ad libitum.

On the day before study each dog was fasted and water was withheld. On the morning of study the conscious dog was weighed and placed on its side on a covered surgical table. A urethral catheter was inserted for the collection of urine and a polyethylene catheter was placed into a hind leg vein for blood sampling. Another polyethylene catheter was introduced into the right atrium via the right jugular vein for the determination of cardiac output. Next a 20gauge Longdwell catheter was inserted into the exteriorized carotid artery for measurement of arterial pressure and heart rate with a Statham transducer (Statham Instruments Inc., Oxnard, Calif.) and cardiac output with dye-dilution techniques (19). At the beginning of each study a bolus of inulin was given intravenously and urine collections were taken over the next hour. Blood samples were obtained at the end of each urine collection for estimating extracellular fluid volume by calculating inulin space (20). Control cardiac outputs also were obtained at this time. Control clearance measurements were obtained after a 15-20-min equilibration period during which a solution of $0.9 \%$ saline containing sufficient inulin and $p$-aminohippurate $(\mathrm{PAH})$ for clearance measurements was administered at $0.5 \mathrm{ml} / \mathrm{min}$ intravenously. Three control urine samples were collected at 10 -min intervals and blood samples for clearance calculations and vasopressin activity were collected at the midpoint of the first and third urine collection. Mean arterial pressure and heart rate determinations were done at the midpoint of each urine collection. After the control urine collections, a water load totaling $40 \mathrm{mt} / \mathrm{kg}$ of $2.5 \%$ dextrose in water was administered intravenously over the next $45-60 \mathrm{~min}$. At the end of the water load and during the maximum water diuresis, as ascertained by no further decrease in urinary osmolality, three experimental 10-min urine collections were obtained and blood samples drawn during the first and third urine collections. Again, arterial pressure and pulse were recorded during each urine collection. Cardiac output was measured after the urine collections.

Several days before study, each dog was allowed to receive a water load to accustom them to the protocol. Each animal was studied in the following two states:

Group I. Control studies in which animals received both DOCA and DEX replacement.

Group II. Experimental studies in which animals received DOCA replacement only; DEX had been withdrawn for 5 days in four animals and for 9 days in two animals.

In both group I and group II studies, three animals were studied once and three animals were studied twice, in a random order. The methods for analysis of inulin, PAH, electrolytes, and osmolality have been referred to elsewhere (21) and clearances were calculated in the conventional manner. Plasma AVP levels were measured by radioimmunoassay (22). The plasma cortisol levels were measured by competitive protein-binding radioassay (23). Statistical analysis was performed by the Student paired $t$ test.

\section{RESULTS}

Effect of glucocorticoid hormone deficiency on the response to an acute water load. The results of an acute water load of $40 \mathrm{ml} / \mathrm{kg}$ in the group I vs. the group II studies are shown in Fig. 1. In the group I studies in glucocorticoid animals urinary osmolality (Uosm) fell from $1,086 \pm 149$ to $82 \pm 4 \mathrm{mosmol} / \mathrm{kg} \mathrm{H}_{2} \mathrm{O}(P<0.001)$ and free water clearance $\left(\mathrm{CH}_{2} \mathrm{O}\right)$ increased from $-1.38 \pm 0.20$ to $6.51 \pm 0.72 \mathrm{ml} / \mathrm{min} \quad(P<0.001)$. In contrast, the glucocorticoid-deficient animals were unable to dilute their urine maximally, as Uosm fell only from $742 \pm 47$ to $425 \pm 56 \mathrm{mosmol} / \mathrm{kg} \mathrm{H}_{2} \mathrm{O}(P<0.01)$ and $\mathrm{CH}_{2} \mathrm{O}$ increased only from $-0.72 \pm 13$ to $-0.05 \pm 0.16$ $\mathrm{ml} / \mathrm{min}(P<0.02)$. Osmolar clearance (Cosm) fell slightly in groups I and II after the water load from $2.09 \pm 0.14$ to $1.32 \pm 0.21 \mathrm{ml} / \mathrm{min}(P<0.05)$ vs. $2.36 \pm 0.29$ to $1.18 \pm 0.23 \mathrm{ml} / \mathrm{min}(P<0.001)$, respectively. In group I studies, plasma osmolality (Posm) fell from $311 \pm 2$ to $308 \pm 2$ mosmol/ $\mathrm{kg} \mathrm{H}_{2} \mathrm{O}(P<0.02)$ and plasma AVP levels decreased appropriately from $1.12 \pm 0.27$ to $0.34 \pm 0.08 \mathrm{pg} / \mathrm{ml}(P<0.02)$. However, in the group II studies in glucocorticoid-deficient animals, despite a greater decrement in Posm from $317 \pm 5 \mathrm{mosmol} / \mathrm{kg} \mathrm{H}_{2} \mathrm{O}$ to $305 \pm 5 \mathrm{mosmol} / \mathrm{kg}(P<0.001)$, the plasma AVP levels were not suppressed and actually rose from $3.85 \pm 1.36$ to $9.13 \pm 1.79 \mathrm{pg} / \mathrm{ml}(P<.01)$. The decrement in Posm after the water load in groups I and II and the corresponding changes in plasma AVP are illustrated in Fig. 2. The concomitant modest fall in Uosm was compatible with a nonvasopressin-mediated effect of water loading, such as diminution in medullary tonicity, which may account for this acute vasopressin escape phenomenon.

Effect of glucocorticoid hormone on renal hemodynamics and body weight. As shown in Table I, clearances of inulin (glomerular filtration rate, GFR) and PAH (CPAH) were comparable in the groups I and II studies. The weights also were not different in both groups of animals. Inulin spaces measured in five animals were not significantly different in groups I and II, $6,085 \pm 124$ vs. $5,380 \pm 467 \mathrm{ml}$, respectively. After the water load neither GFR nor CPAH changed significantly in groups I and II.

Effect of glucocorticoid hormone deficiency on systemic hemodynamics. Blood pressure, cardiac output, and peripheral vascular resistance in groups I and II studies are compared in Fig. 3 before the water load. None of these parameters were different between groups I and II. However, because of a significantly greater pulse rate of $89 \pm 7$ vs. $69 \pm 4$ beats/ 


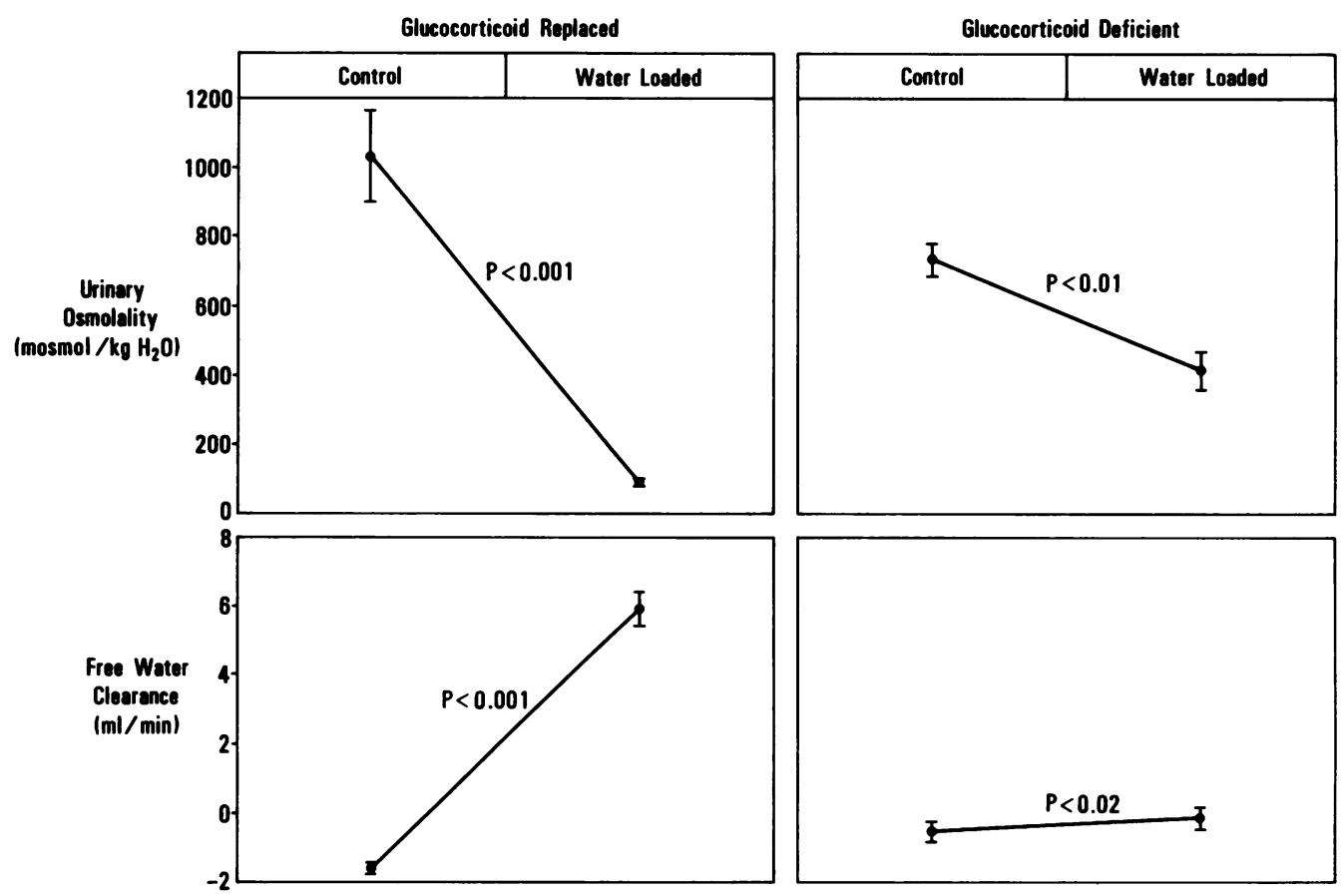

FIGURE 1 Effect of an acute water load on Uosm and $\mathrm{CH}_{2} \mathrm{O}$ in group I studies (left panel) and in group II studies (right panel). Glucocorticoid deficiency (group II) led to a higher minimal Uosm and a lower $\mathrm{CH}_{2} \mathrm{O}$ after water loading as compared to hormone-replaced studies (group I).

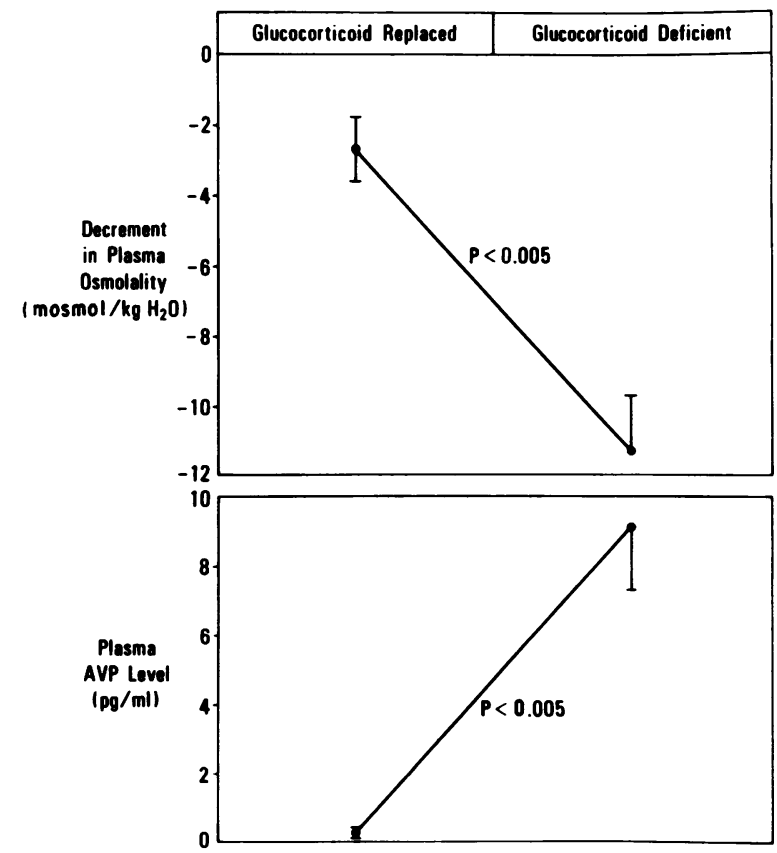

Figure 2 Effect of an acute water load on Posm and plasma AVP in group I studies (left panel) and group II studies (right panel). Despite a greater decrement in Posm as compared to group I, plasma AVP remained elevated in the group II studies. $\min (P<0.01)$ in group II animals the stroke volume was lower in the group II than group I studies $(33 \pm 0.3$ vs. $59 \pm 0.3 \mathrm{ml} /$ beat, $P<0.01)$ as shown in Fig. 4. Likewise, after the water load, the pulse rate of the group II animals was significantly higher than in the group I animals ( $145 \pm 6$ vs. $87 \pm 6$ beats $/ \mathrm{min}, P<0.001$ ) and the stroke volume significantly lower $(27 \pm 0$ vs. $59 \pm 5 \mathrm{ml} /$ beat, $P<0.001$ ). Cardiac output increased significantly in group I studies from $3.8 \pm 0.5$ before to $4.9 \pm 0.7$ liters $/ \mathrm{min}$ after the water load $(P<0.02)$. However in group II studies, despite the water load, the cardiac output did not increase significantly being 3.0 \pm 0.3 before vs. $3.6 \pm 0.5$ liters $/ \mathrm{min}$ after the water load $(P>0.05 \mathrm{NS})$. In addition to changes in stroke volume and heart rate, in five out of nine animals in group II studies blood pressure fell during the acute water load. However, in the group as a whole there was no statistically significant decrease in blood pressure before or after the water load.

\section{DISCUSSION}

The purpose of this study was to delineate the effect of selective glucocorticoid deficiency on renal water excretion. Some features of the experimental design are worthy of emphasis. All animals served as their own control and were studied in the conscious state 
TABLE I

The Effect of Withdrawal of Glucocorticoid Hormone on GFR, CPAH, and Body Weight in Adrenalectomized Conscious Dogs

\begin{tabular}{|c|c|c|c|c|c|c|}
\hline & \multicolumn{2}{|c|}{ CIN } & \multicolumn{2}{|c|}{ CPAH } & \multicolumn{2}{|c|}{ Body weight } \\
\hline & $\begin{array}{l}\text { Gluco } \\
\text { replaced }\end{array}$ & $\begin{array}{c}\text { Gluco } \\
\text { deficient }\end{array}$ & $\begin{array}{l}\text { Gluco } \\
\text { replaced }\end{array}$ & $\begin{array}{c}\text { Gluco } \\
\text { deficient }\end{array}$ & $\begin{array}{l}\text { Gluco } \\
\text { replaced }\end{array}$ & $\begin{array}{c}\text { Gluco } \\
\text { deficient }\end{array}$ \\
\hline & \multicolumn{2}{|c|}{$\mathrm{ml} / \mathrm{min}$} & \multicolumn{2}{|c|}{$\mathrm{ml} / \mathrm{min}$} & \multicolumn{2}{|c|}{ kg } \\
\hline $\begin{array}{l}\text { Mean } \\
\pm \text { SE }\end{array}$ & $\begin{array}{r}86.6 \\
\pm 4.6\end{array}$ & $\begin{array}{r}77.5 \\
\pm 16.1\end{array}$ & $\begin{array}{r}288 \\
\pm 23\end{array}$ & $\begin{array}{r}328 \\
\pm 84\end{array}$ & $\begin{array}{l}22.8 \\
\pm 1.02\end{array}$ & $\begin{array}{l}24.3 \\
\pm 1.36\end{array}$ \\
\hline$P$ value & \multicolumn{2}{|c|}{ NS } & \multicolumn{2}{|c|}{ NS } & \multicolumn{2}{|c|}{ NS } \\
\hline
\end{tabular}

Abbreviations used in this table: CIN, clearance of inulin; Gluco, glucocorticoid.

both with and without glucocorticoid replacement. In all studies the dogs were adequately replaced with mineralocorticoid hormone, thus avoiding extracellular fluid volume depletion. In this regard, body weight, inulin spaces, and plasma sodium concentration in group I and II studies were comparable. Also, in contrast to many previous studies, adequate systemic and renal hemodynamic measurements were made in each study both in the glucocorticoid-replaced and -deficient states. Finally, this is the first investigation in which plasma vasopressin was measured by a sensitive radioimmunoassay rather than bioassay techniques $(8,9,16,17)$.

In the control or group I studies, the acute water load was associated with normal urinary dilution as ascertained by a very low Uosm and by a markedly

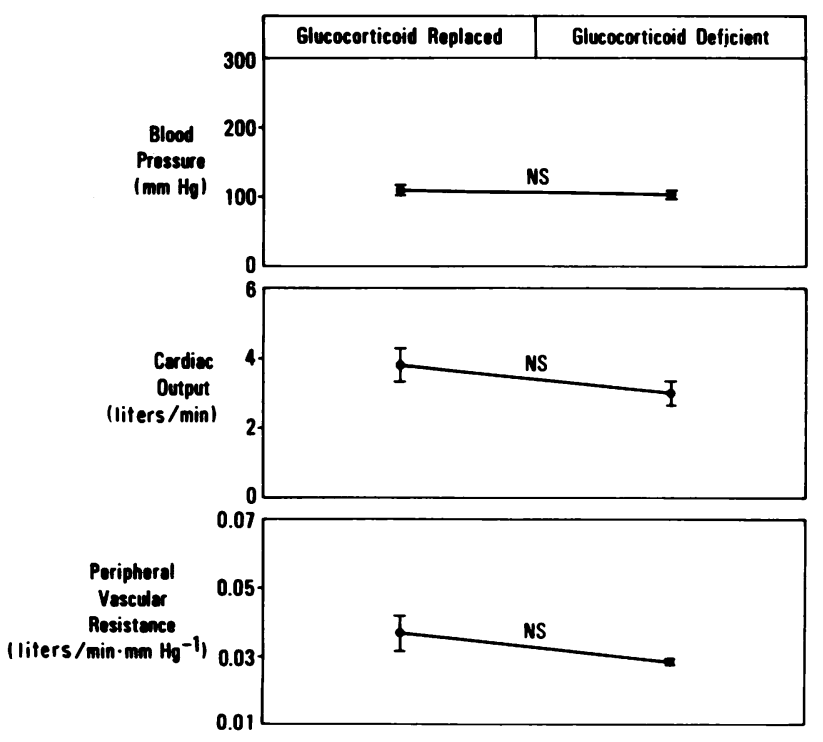

FIGURE 3 Effect of withdrawal of glucocorticoid hormone on blood pressure, cardiac output, and peripheral vascular resistance in adrenalectomized dogs. None of these hemodynamic parameters were different between the group I and group II studies. elevated $\mathrm{CH}_{2} \mathrm{O}$. Concomitantly, the circulating levels of plasma vasopressin fell significantly from 1.12 to 0.34 $\mathrm{pg} / \mathrm{ml}$, indicating an adequate suppressibility of AVP release. Stroke volume, renal blood flow, and GFR were unchanged during the water loading in the group I studies.

In contrast, in the group II studies when the animals were glucocorticoid deficient for 5-9 days, the response to the acute water load was markedly abnormal. Uosm failed to decrease below plasma osmolality and $\mathrm{CH}_{2} \mathrm{O}$ remained negative. This profound impairment of renal water excretion occurred despite a comparable GFR, renal blood flow, body weight, and inulin space as in group I control studies. In con-

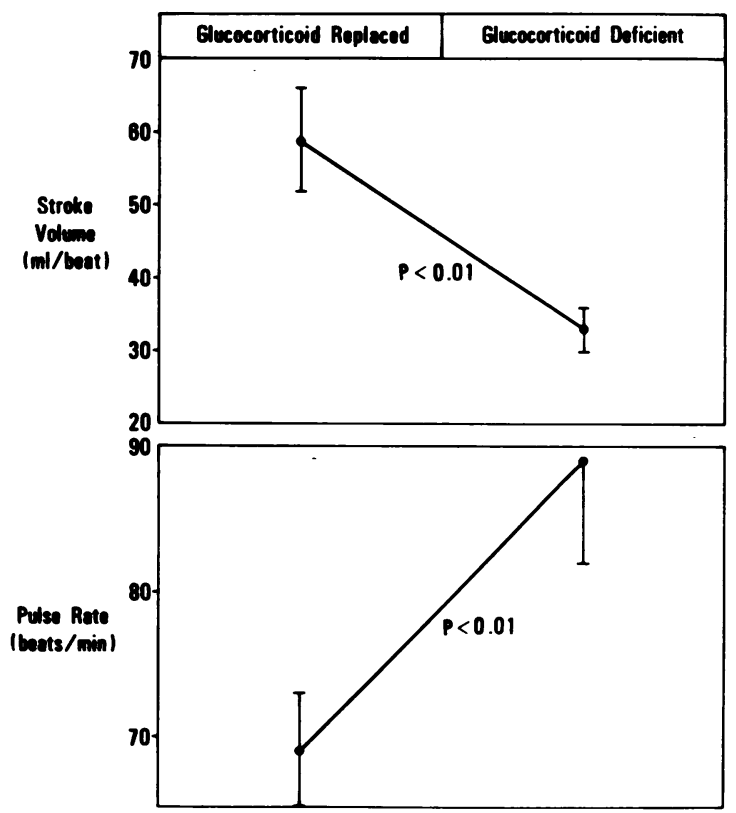

FIGURE 4 Effect of withdrawal of glucocorticoid hormone on stroke volume and pulse rate in adrenalectomized dogs. Glucocorticoid withdrawal (group II) resulted in a higher pulse rate and a lower stroke volume as compared to the glucocorticoid-replaced studies (group I). 
trast to previous suggestions, these results seemed to exclude extracellular fluid volume depletion as a factor in abnormal water excretion associated with glucocorticoid deficiency. Even though Posm fell markedly during the water load in the glucocorticoid deficiency studies, the expected suppression of AVP release by this hypoosmolar stimulus did not occur. In fact, plasma AVP actually increased significantly during the acute water loading.

It seems likely, therefore, that glucocorticoid deficiency facilitates a nonosmolar stimulus which predominates over the hypoosmolar stimulus of water loading and causes persistent release of plasma AVP. In support of this conclusion are the recent published results of Seif et al. (24). With immunohistochemical staining techniques, these workers found increased amounts of vasopressin in the hypothalamus but decreased amounts of vasopressin in the posterior pituitary of glucocorticoid deficient rats. They, therefore, proposed that glucocorticoid deficiency is associated with increased hypothalamic synthesis and pituitary release of vasopressin. Also compatible with this interpretation are the earlier findings of Dingman and Despointes (10). These workers studied patients with adrenal insufficiency whose glucocorticoid replacement had been withdrawn. They found increased bioassayable titers of AVP, some of which were extraordinarily high. The patients also were found to have increased sensitivity to the effect of nicotine on water excretion, an effect which could be reversed by glucocorticoid replacement. Since the nonosmolar influence of nicotine on vasopressin release was felt to be a direct central effect, it was not unreasonable to propose that glucocorticoid deficiency exerts its effect by a similar pathway. The results of recent studies in dogs from our laboratory, however, have demonstrated that nicotine-induced release of vasopressin is dependent upon intact baroreceptor pathways (25). No direct central effect of nicotine could be demonstrated, because the intracarotid infusion of large doses of nicotine above the level of the baroreceptors failed to alter renal water excretion (25). It is, therefore, possible that glucocorticoid deficiency could also lead to persistent release of vasopressin by a similar baroreceptor-mediated pathway. Since the present experimental protocol used the same conscious dogs as their own control, acute baroreceptor denervation including bilateral cervical vagotomy was not possible. There was, however, indirect evidence of increased sympathetic tone in the glucocorticoid-deficient studies, because the heart rates were higher in these animals. In the absence of evidence for extracellular fluid volume depletion, the effect of glucocorticoid deficiency to impair cardiac function (26-29) seems the likely initiating event for increased sympathetic tone in the glucocorticoid deficiency state. In this regard, it is interesting to note that not only were the plasma vasopressin levels higher and stroke volume lower in the glucocorticoid-deficient state, but these parameters actually increased and decreased, respectively, during acute water loading.

In contrast, plasma vasopressin was maximally suppressed and stroke volume was unchanged with acute water loading in the studies performed in the glucocorticoid-replaced animals.

It is attractive to postulate that glucocorticoid deficiency stimulates the nonosmotic release of vasopressin by altering baroreceptor tone because several nonosmotic stimuli for vasopressin release have been demonstrated to be mediated by these baroreceptor pathways. In addition to nicotine (25), these stimuli include systemic alpha (30) and beta (31) adrenergic stimulation, acute constriction of the thoracic inferior vena cava (32), left atrial distention (33), atrial tachycardia (34), and hypoxia (35). From these results has emerged the hypothesis that the nonosmotic release of vasopressin may have evolved as an integral part of the alarm reaction (36). Thus, the circumstances which are associated with increased sympathetic tone such as emotional and physical stress, cardiac failure, hemorrhage, and adrenal insufficiency may cause diminished vagal afferent tone, an effect known to stimulate vasopressin release (37).

Analysis of the present results with previous studies from our laboratory in conscious adrenalectomized dogs (18) provides information about the separate effects of glucocorticoid and mineralocorticoid hormone. Mineralocorticoid deficiency in the presence of glucocorticoid replacement was shown previously to impair renal water excretion (18). This effect of mineralocorticoid hormone on water excretion was shown to be related to extracellular volume depletion, an effect which proved to be mediated both by vasopressin release and a fall in glomerular filtration rate (38). Glucocorticoid hormone withdrawal in the mineralocorticoid-replaced animal also was shown to be compatible with normal renal water excretion for as long as 3 days (18). The present results demonstrate, however, that glucocorticoid deficiency for 5-9 days consistently impairs water excretion. Such a duration of time may be necessary for the effects of glucocorticoid hormone deficiency to cause myocardial dysfunction and thereby trigger nonosmolar, baroreceptormediated vasopressin release. In any case, it is quite clear that the effects whereby adrenal insufficiency impairs renal water excretion can only be delineated when glucocorticoid and mineralocorticoid deficiency are considered separately.

The results of the present study are compatible with the observation of Agus and Goldberg (15) in two patients suffering from anterior hypopituitarism. In these patients the administration of ethanol, an inhibi- 
tor of vasopressin release, improved their defect in urinary dilution. Ahmed et al. (9) also found elevated bioassayable titer of vasopressin in clinical adrenal insufficiency which were diminished by pharmacological replacement of glucocorticoid hormones. In a recently published preliminary report, Mandell et al. (39) also found an incomplete suppression of radioimmunoassayable AVP during a water load in hypophysectomized rats. On the other hand, Kleeman et al. (8) have been unable to find detectable levels of vasopressin in patients and dogs with adrenal insufficiency. Ahmed et al. (9) attributed this failure to detect plasma vasopressin levels in the patients with adrenal insufficiency to an insensitivity of the vasopressin bioassay technique used. Even if this were the situation, the studies of Green et al. (13) in Brattleboro rats with hereditary diabetes insipidus that were adrenalectomized seem to incriminate a vasopressin-independent pathway whereby both glucocorticoid and mineralocorticoid may impair water excretion. Thus, while the present results incriminate a role of vasopressin in mediating the impaired water excretion of glucocorticoid deficiency an additional tubular effect of glucocorticoid hormone is not excluded and would seem likely. Systemic and renal hemodynamics were not measured in the study of Green et al. (13) and, therefore, depressed systemic and renal hemodynamics could have mediated indirectly the effect of glucocorticoid deficiency on tubular water reabsorption. Kurokawa et al. (40), however, have recently performed in vitro studies in which glucocorticoid deficiency enhanced the effect of vasopressin to increase medullary $3^{\prime} 5^{\prime}$ adenosine monophosphate, thus suggesting a direct tubular effect. Additional studies performed in vivo will be necessary, however, to investigate the nature of any vasopressin-independent effect on renal tubular water movement.

In summary, the present results demonstrate that persistently elevated plasma levels of vasopressin, as measured with the sensitive radioimmunoassay technique, are involved in the impaired water excretion associated with 5-9 days of glucocorticoid deficiency in mineralocorticoid-replaced dogs. These elevated levels of plasma vasopressin were dissociated from any decrease in body weight, extracellular fluid volume, or clearances of inulin and PAH. A consistent and significant diminution in stroke volume and tachycardia in the glucocorticoid-deficient state, however, was associated with the elevated plasma vasopressin levels and thus was compatible with nonosmolar baroreceptor-mediated vasopressin release. The present results should, however, not be interpreted to exclude an additional vasopressin-independent effect of glucocorticoid deficiency on water excretion, either as mediated indirectly by hemodynamic alterations or by a direct effect on tubular water permeability.

\section{ACKNOWLEDGMENTS}

The authors would like to express their appreciation to Ms. Janet Genow for her secretarial assistance and to Dr. Warren W. Frost for assistance in performing the bilateral adrenalectomies in dogs.

This study was supported by grants HL 15629-02 and 5T32 AM 07135-02, both from the National Institutes of Health.

\section{REFERENCES}

1. Kottke, F. J., C. F. Code, and E. H. Wood. 1942. Urine dilution and concentration tests in adrenalectomized dogs. Am. J. Physiol. 136: 229-243.

2. Roemmelt, J. D., O. W. Sartorius, and R. F. Pitts. 1949. Excretion and reabsorption of sodium and water in the adrenalectomized dog. Am. J. Physiol. 159: 124-136.

3. Garrod, O., and R. A. Burston. 1952. The diuretic response to ingested water in Addison's disease and panhypopituitarism and the effect of cortisone thereon. Clin. Sci. (Oxf.). 2: 113-128.

4. Garrod, O., S. A. Davies, and G. Cahill, Jr. 1955. The action of cortisone and desoxycorticosterone acetate on glomerular filtration rate and sodium and water exchange in the adrenalectomized dog.J. Clin. Invest. 34: 761-776.

5. Kleeman, C. R., M. H. Maxwell, and R. E. Rockney. 1958. Mechanisms of impaired water excretion in adrenal and pituitary insufficiency. I. The role of altered glomerular filtration rate and solute excretion. J. Clin. Invest. 37: 1799-1808.

6. Kleeman, C. R., J. Koplowitz, M. H. Maxwell, R. Cutler, and J. T. Dowling. 1960. Mechanisms of impaired water excretion in adrenal and pituitary insufficiency. II. Interrelationships of adrenal cortical steroids and antidiuretic hormone in normal subjects and in diabetes insipidus. J. Clin. Invest. 39: 1472-1480.

7. Cutler, R. E., C. R. Kleeman, J. Koplowitz, M. H. Maxwell, and J. T. Dowling. 1962. Mechanisms of impaired water excretion in adrenal and pituitary insufficiency. III. The effect of extracellular or plasma volume expansion or both, on the impaired diuresis. J. Clin. Invest. 41: 1524-1530.

8. Kleeman, C. R., J. W. Czaczkes, and R. Cutler. 1964. Mechanisms of impaired water excretion in adrenal and pituitary insufficiency. IV. Antidiuretic hormone in primary and secondary adrenal insufficiency. J. Clin. Invest. 43: $1641-1648$.

9. Ahmed, A. B., B. C. George, C. Gonzalez-auvert, and J. F. Dingman. 1967. Increased plasma arginine vasopressin in clinical adrenocortical insufficiency and its inhibition of glucosteroids. J. Clin. Invest. 46: 111-123.

10. Dingman, J. F., and R. H. Despointes. 1960. Adrenal steroid inhibition of vasopressin release from the neurohypophysis of normal subjects and patients with Addison's disease. J. Clin. Invest. 39: 1851-1863.

11. Gaunt, R., J. H. Birnie, and W. J. Eversole. 1949. Adrenal cortex and water metabolism. Physiol. Rev. 29: 281-310.

12. Stolte, H., J. P. Brecht, M. Wiederhold, and K. Hierholzer. 1968. Einfluss von adrenalektomie and glucocorticoiden auf die wasserpermeabilitat corticaler nephroabschnitte der rattenniere. Pfluegers Archiv. Gesamte Physiol. Menschen Tiere. 299: 99-127.

13. Green, H. H., A. R. Harrington, and H. Valtin. 1970. On the role of antidiuretic hormone in the inhibition of acute water diuresis in adrenal insufficiency and the effects of gluco- and mineralocorticoids in reversing the inhibition. J. Clin. Invest. 49: 1724-1736. 
14. Gill, J. R., Jr., D. S. Gann, and F. C. Bartter. 1962. Restoration of water diuresis in Addisonian patients by expansion of the volume of extracellular fluid. J. Clin. Invest. 41: 1078-1085.

15. Agus, Z. S., and M. Goldberg. 1971. Role of antidiuretic hormone in the abnormal water diuresis of anterior hypopituitarism in man. J. Clin. Invest. 50: 1478-1489.

16. Levi, J., J. Grinblat, and C. R. Kleeman. 1973. Water diuresis in the volume expanded glucocorticoid-deficient dog. Isr. J. Med. Sci. 9: 429-437.

17. Share, L., and R. H. Travis. 1970. Plasma vasopressin concentration in the adrenally insufficient dog. Endocrinology. 86: 196-201.

18. Ufferman, R. C., and R. W. Schrier. 1972. Importance of sodium intake and mineralocorticoid hormone in the impaired water excretion in adrenal insufficiency. J. Clin. Invest. 51: 1639-1646.

19. Schrier, R. W., and M. H. Humphreys. 1971. Factors involved in the antinatriuretic effects of acute constriction of the thoracic and abdominal inferior vena cava. Circ. Res. 29: 479-489.

20. Poulos, P. P. 1956. A constant change (single injection) method for the estimation of the volume of distribution of substances in body fluid compartments. J. Clin. Invest. 35: $921-933$.

21. Anderson, R. J., M. S. Taher, R. E. Cronin, K. McDonald, and R. W. Schrier. 1975. Effect of $\beta$-adrenergic blockade and inhibitors of angiotensin II and prostaglandins in renal autoregulation. Am. J. Physiol. 229: 731-736.

22. Robertson, G. L., E. A. Mahr, S. Athat, and T. Sinha. 1973. Development and clinical application of a new method for the radioimmunoassay or arginine vasopressin in human plasma. J. Clin. Invest. 52: 2340-2352.

23. Murphy, B. E. P. 1967. Some studies of the protein binding of steroids and their application to the routine micro and ultramicro measurement of various steroids in body fluids by competitive protein binding radioassay. J. Clin. Endocrinol Metab. 27: 973-990.

24. Seif, S. M., A. B. Huellmantel, M. Stillman, L. Recht, and A. G. Robinson. 1977. Neurophysin and vasopressin in the plasma and hypothalamus of adrenalectomized and normal rats. Endocrinology. 101: 42-49.

25. Cadnapaphornchai, P., J. J. Boykin, T. Berl, K. M. McDonald, and R. W. Schrier. 1974. Mechanism of effect of nicotine on renal water excretion. Am. J. Physiol. 227: 1216-1220.

26. Reidenberg, M. M., E. A. Ohler, R. W. Seuy, and C. Harakal. 1963. Hemodynamic changes in adrenalectomized dogs. Endocrinology. 72: 918-923.
27. Clarke, A. P. W., R. A. Cleghorn, J. K. W. Ferguson, and J. L. A. Fowler. 1947. Factors concerned in the circulatory failure of adrenal insufficiency. J. Clin. Invest. 26: $359-363$.

28. Lefer, A. M., R. L. Verrier, and W. W. Carson. 1968. Cardiac performance in experimental adrenal insufficiency in cats. Circ. Res. 22: 817-827.

29. Lefer, A. M. 1968. Influence of corticosteroids on mechanical performance of isolated rat papillary muscles. Am. J. Physiol. 214: 518-524.

30. Berl, T., P. Cadnapaphornchai, J. A. Harbottle, and R. W. Schrier. 1973. Mechanism of suppression of vasopressin during alpha-adrenergic stimulation with norepinephrine. J. Clin. Invest. 53: 219-227.

31. Berl, T., P. Cadnapaphornchai, J. A. Harbottle, and R. W. Schrier. 1974. Mechanism of stimulation of vasopressin release during beta adremergic stimulation with isoproterenol. J. Clin. Invest. 53: 857-867.

32. Anderson, R. J., P. Cadnapaphornchai, T. Harbottle, K. McDonald, R. W. Schrier. 1974. Mechanism of effect of thoracic inferior vena cava constriction on renal water excretion. J. Clin. Invest. 54: 1473-1479.

33. deTorrenté, A., G. L. Robertson, K. McDonald, and R. W. Schrier. 1975. Mechanism of diuretic response to increased left atrial pressure in the anesthetized dog. Kidney Int. 8: 355-361.

34. Boykin, T., P. Cadnapaphornchai, K. McDonald, and R. W. Schrier. 1975. Mechanism of diuretic response associated with atrial tachycardia. Am. J. Physiol. 229: 1486-1491.

35. Anderson, R. J., R. G. Pluss, A. S. Berns, J. T. Jackson, P. E. Arnold, R. W. Schrier, and K. M. McDonald. 1978. Mechanism of effect of hypoxia on renal water excretion. J. Clin. Invest. 62: 769-777.

36. Schrier, R. W. 1974. "Inappropriate" versus appropriate antidiuretic hormone secretion. West. J. Med. 121: 62-64.

37. Schrier, R. W., and T. Berl. 1972. Mechanism of the antidiuretic effect associated with interruption of parasympathetic pathways. J. Clin. Invest. 51: 2613-2620.

38. Boykin, T., A. McCool, G. Robertson, K. McDonald, and $R$. Schrier. 1975. Mechanism of impaired water excretion in mineralocorticoid deficient dogs. Clin. Res. 23: 233A. (Abstr.)

39. Mandell, I., R. DeFronzo, G. Robertson, and J. N. Forrest, Jr. 1977. Incomplete suppression of plasma arginine vasopressin (pAVP) during water diuresis in glucocorticoid deficiency. American Society of Nephrology, 10th Annual Meeting, Washington, D. C. 114A.

40. Kurokawa, K., E. Azner, C. Descoeudres, and S. Massry. 1978. Effects of glucocorticoid deficiency on renal medullary cyclic AMP. Clin. Sci. Mol. Med. 54: 573-577. 